\title{
Prenatal Diagnosis of Craniomaxillofacial Malformations: A Characterization of Phenotypes in Trisomies 13, 18, and 21 by Ultrasound and Pathology
}

\author{
A.M. Ettema, M.D., Ph.D., M. Wenghoefer, M.D., D.M.D., M. Hansmann, M.D., Ph.D., C.E.L. Carels, D.M.D., Ph.D., \\ W.A. Borstlap, M.D., D.M.D., Ph.D., S.J. Bergé, M.D., D.M.D., Ph.D.
}

\begin{abstract}
Objective: To determine the relationship between trisomies 13, 18, and 21 and craniofacial malformations detected by prenatal sonography.

Design: During a 29-year period (1976 through 2004), prenatal sonographic findings of 69 fetuses with trisomy 13; 171 fetuses with trisomy 18; 302 fetuses with trisomy 21 ; and 17 fetuses with other trisomies were evaluated retrospectively, after fetal karyotype identification. Sonographic findings were compared with autopsy results in 209 patients (trisomy 13, $n=39$; trisomy 18, $\mathrm{n}=64$; and trisomy $21, \mathrm{n}=106$ ).

Results: For trisomy 13, cleft deformities were detected prenatally in $65.2 \%$, and of the 39 cases with pathological information, $76.9 \%$ were found to have a cleft deformity. Ocular and orbital abnormalities were found in $28 \%$. Malformations of the jaws and abnormal profiles were more frequently diagnosed postnatally than prenatally. For trisomy 18 , abnormal profiles $(41.5 \%)$ and ear abnormalities (5.3\%) were the most noticeable ultrasound markers, next to abnormalities of the neurocranium $(36.8 \%)$ and cranial bone configuration $(21.6 \%)$. Dysmorphisms of the eye, ear, or nose were detected more frequently in autopsy cases. For trisomy 21, ultrasound showed an aberrant shape of the skull in $14.2 \%$ of fetuses. In general, the ocular-orbital and nasal abnormalities in fetuses with trisomy 18 or $\mathbf{2 1}$ were more evident in pathological examination than in prenatal ultrasound imaging.

Conclusions: Facial anomalies are common in the major trisomies, and their prenatal sonographic identification should be improved. The above-mentioned facial anomalies provide sufficient reason to consider performing cytogenic evaluation.
\end{abstract}

KEY WORDS: facial malformations, fetal aneuploidy, prenatal sonography, trisomy

Trisomies 21, 18, and 13 are the most commonly diagnosed autosomal trisomies in liveborn infants. Although these conditions are associated with a high degree

Dr. Ettema is Resident, Department of Oral and Maxillofacial Surgery, Radboud University Nijmegen Medical Center, Nijmegen, The Netherlands. Dr. Wenghoefer is Resident, Department of Oral and Maxillofacial Plastic Surgery, University of Bonn, Bonn, Germany. Dr. Hansmann is Professor, Department of Obstetrics and Gynecology, Division of Prenatal Diagnosis and Therapy, University of Bonn, Bonn, Germany. Dr. Carels is Professor, Department of Orthodontics and Oral Biology, Radboud University Nijmegen Medical Center, Nijmegen, The Netherlands, and Department of Orthodontics, Catholic University of Leuven, Leuven, Belgium. Dr. Borstlap is Surgeon and Dr. Bergé is Professor, Department of Oral and Maxillofacial Surgery, Radboud University Nijmegen Medical Center, Nijmegen, The Netherlands.

Submitted July 2009; Accepted August 2009.

Address correspondence to: Prof.dr. Stefaan J. Bergé, Department of Oral and Maxillofacial Surgery, Radboud University Nijmegen Medical Center, Geert Grooteplein-Zuid 14, 6500 HB Nijmegen, The Netherlands. E-mail S.Berge@mka.umcn.nl.

DOI: $10.1597 / 08-285.1$ of infant mortality, longer survival, especially in the case of trisomy 21, is quite common nowadays (Rasmussen et al., 2003).

Each trisomic condition has a typical phenotype that nevertheless shows a wide variation in phenotypic expression. However, the face in particular plays an important role in defining the phenotype. Facial abnormalities are, for example, quite common among fetuses with trisomy 21 . In 2002, Sonek and Nicolaides reported three cases of trisomy 21 with an absence of or shorter nasal bone than would be expected for the gestational age (Sonek and Nicolaides, 2002). Trisomy 18 is associated with typical facial abnormalities such as short ear length, an abnormal profile, micrognathia, and hypotelorism (Yeo et al., 2003). Also, facial abnormalities due to holoprosencephaly as well as different types of facial clefts as typical signs of trisomy 13 have been described (Nicolaides et al., 1993b; Nyberg and Souter, 2001). With the improving quality of ultrasound equipment and standards of scanning, craniofacial dysmorphisms are more likely to be detected, even by routine ultrasound examination. 
TABLE 1 Screening Index of Markers for Detecting Trisomies 13, 18 , and 21

\begin{tabular}{ll}
\hline Abnormal skull & Facial clefts, cleft lip, or cleft palate \\
Macrocephaly or microcephaly & Median cleft \\
Brachycephaly & Microstomia \\
Strawberry skull & Ocular or orbital abnormalities \\
Polyhydramnion* & Anophthalmia \\
Abnormal neurocranium & Microphthalmia \\
Holoprosencephaly & Hypotelorism or hypertelorism \\
Hydrocephalus & Nasal abnormalities \\
Choroid plexus cysts & Single nostril \\
Nuchal edema or translucency & No nasal bone \\
Facial defects & Ear abnormalities \\
Flat forehead & Retrocaudal positioning of the ears \\
Flat or abnormal profile & Low-set ears or small ears \\
Micrognathia & Cardiac abnormality* \\
Macroglossia & \\
\hline
\end{tabular}

* Not included in this study.

The aim of this study was to determine the relationship between major trisomic conditions and prenatally detected craniofacial malformations.

\section{Patients and Methods}

The patients were recruited at the Department of Obstetrics and Gynecology, Division of Prenatal Diagnosis and Therapy in a Level III hospital from 1976 through 2004. During the study period, 559 fetuses with trisomies 21 $(\mathrm{n}=302), 18(\mathrm{n}=171), 13(\mathrm{n}=69)$, and others $(\mathrm{n}=17)$ were evaluated sonographically according to an index of facial and cranial markers for detecting trisomies (Table 1). Postnatal autopsies were performed in a subset of 209 fetuses. All the cytogenetic and ultrasound records of these fetuses were reviewed and analyzed retrospectively. In the first years of the study, besides sonographic examination, the patients underwent an amniocentesis between gestational weeks 12 and 39 in order to determine the fetal karyotype. Since 1987, the techniques of cordocentesis and placental biopsy also have been used.

Examination of the fetal face was done by a transabdominal ultrasound technique and performed by welltrained obstetricians. Different types of ultrasound systems equipped with different transducers were used (e.g., the Sonoline SL 1 and 2 [Siemens AG, Erlangen, Germany]; Acuson 128 [3.5-MHz linear-array transducer], Acuson Aspen [5- to 7-MHz variable-focus transducer], and Acuson Sequoia 512 [5- to 8-MHz sector probes, linear; Acuson Corp., Mountain View, CA]; color doppler ultrasound HDI 5000 [Philips, type ATL, Bothell, WA]; Kretz Combison 530 D [5.0-MHz annular array transducer; Kretztechnik, Zipf, Austria]; Examination of the face always included the midsagittal view for profile analysis and serial axial scans at the level of the forehead, eyes, nose, and upper and lower lips (Hansmann et al., 1991).

The sonograms (usually reports, videotapes, digital data media, and thermal prints) of each case were evaluated for the nature of facial dysmorphism and associated anomalies. If the circumference of the head was below the fifth percentile for the corresponding gestational age, microcephaly was diagnosed. The diagnosis of hydrocephalus was based on an evaluation of the posterior horn of a lateral ventricle. Nuchal edema of more than $3 \mathrm{~mm}$ in the first trimester was regarded as pathological, and, in the case of profound retrognathia, the diagnosis of micrognathia was made without precise measurements. Positioning of the tongue between the lips during most of the time of the ultrasound examination was regarded as macroglossia.

In the case of microphthalmia, the diameter of the eye was smaller than reference values (Hansmann et al., 1991). Hypotelorism was defined as a decreased interocular distance of more than one diameter of the orbita.

The data were obtained by review of the charts, sonograms, and pathological and cytogenetic records. Sonographic data were compared with the autopsy data in case of interruption or neonatal death or with the postnatal clinical findings and detailed information obtained from medical records of the newborn child.

This protocol was approved by our institutional review board, and informed consent was obtained from each patient.

\section{RESULTS}

In cases of fetal trisomy, 69 fetuses with trisomy 13 $(12.3 \%) ; 171$ fetuses with trisomy 18 (30.6\%); and 302 fetuses with trisomy $21(54.0 \%)$ were found. Seventeen cases $(3.0 \%)$ showed other, less common trisomies. Thirtysix, 259, and 264 fetuses were scanned in the periods 1976 through 1983, 1984 through 1992, and 1993 through 2004, respectively. The median gestational age at the time of sonographic examination was 22 (range, 12 to 35) weeks. The mean \pm SD maternal age was $33 \pm 5$ years for trisomy 13 ; $32 \pm 6$ years for trisomy 18 ; and $36 \pm 5$ years for trisomy 21 .

\section{Trisomy $13(\mathrm{n}=69)$}

On detailed ultrasonographic examination, 20 of the 69 fetuses with trisomy 13 showed abnormalities of the shape of the skull such as microcephaly $(\mathrm{n}=10,14.5 \%)$, brachycephaly $(\mathrm{n}=9,13.0 \%)$, or a strawberry-shaped head $(\mathrm{n}=4,5.8 \%)$. In 28 cases $(40.6 \%)$ an abnormal neurocranium was detected, together with holoprosencephaly $(\mathrm{n}=16,23.2 \%)$ or hydrocephalus ( $\mathrm{n}=13,18.8 \%$ ) (Table 2).

Eighteen fetuses had a flat profile (26.1\%), and eight fetuses $(11.6 \%)$ showed micrognathia. Facial clefts were observed in 45 cases $(65.2 \%)$, with a predominance of cleft lip and palate in 36 fetuses (52.2\%). Sonographic examination revealed ocular and orbital abnormalities in 21 fetuses, most frequently microphthalmia $(\mathrm{n}=15,21.7 \%)$, followed by hypotelorism and hypertelorism $(\mathrm{n}=4,5.8 \%$ each). Using ultrasound only, nasal defects were detected in $13.0 \%$ $(n=9)$ and ear malformations in $4.3 \%(n=3)$ (Table 3$)$.

Among the 39 fetuses with trisomy 13 in which an autopsy was performed, $33.3 \%(n=13)$ had an abnormal 


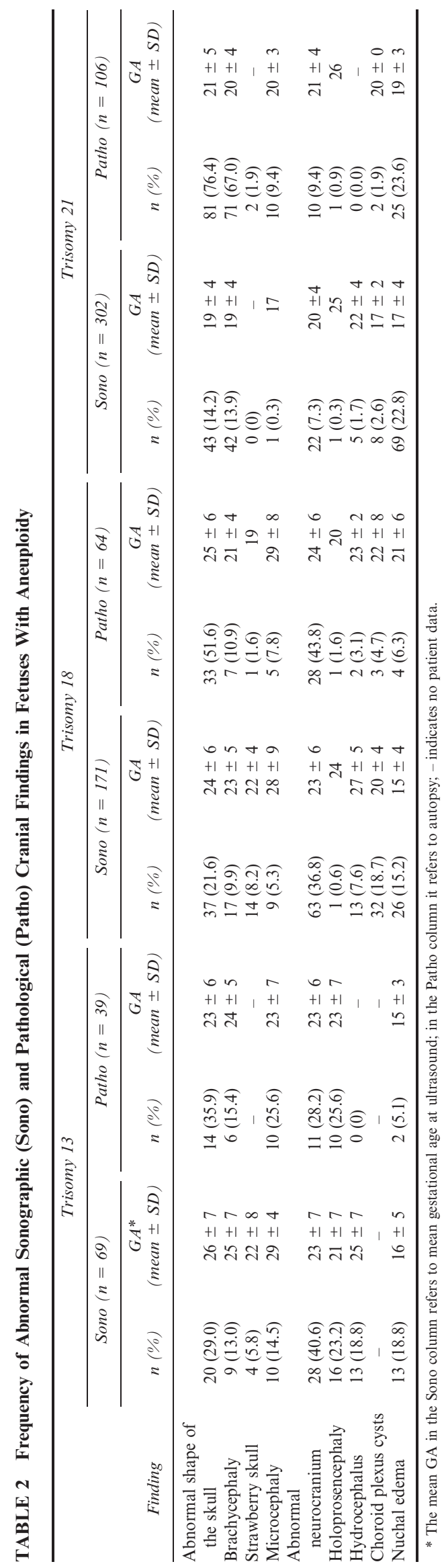

shape of the skull, and $25.6 \%(\mathrm{n}=10)$ had holoprosencephaly. High incidences of flat profile $(\mathrm{n}=29,74.4 \%)$ and facial clefts $(\mathrm{n}=30,76.9 \%)$ were found, including 23 $(59.0 \%)$ fetuses with cleft lip and palate. Ocular-orbital and nasal abnormalities were each found in 11 fetuses (28.2\%) and ear malformations were found in five (12.8\%).

\section{Trisomy $18(\mathrm{n}=171)$}

Thirty-seven fetuses with trisomy $18(21.6 \%)$ showed abnormalities of the shape of the skull, including brachycephaly $(\mathrm{n}=17,9.9 \%)$, strawberry-shaped skull $(\mathrm{n}=14$, $8.2 \%)$, and microcephaly $(\mathrm{n}=9,5.3 \%)$.

The incidence of a flat profile was $41.5 \%(\mathrm{n}=71)$, clearly more frequent ( $p=.025, \chi^{2}$ test) than in trisomy $13(26.1 \%)$ (Tables 2 and 3). Sonographic micrognathia was found in 35 fetuses $(20.5 \%)$. Thirteen $(7.6 \%)$ of the fetuses were suspected prenatally to have a cleft lip and palate, whereas ocular $(\mathrm{n}=7,4.1 \%)$, nasal $(\mathrm{n}=5,2.9 \%)$, and ear abnormalities $(\mathrm{n}=9,5.3 \%)$ were rarely found.

Among the 64 fetuses (37.4\%) who underwent autopsy, $33(51.6 \%)$ showed abnormalities of the shape of the skull, and $28(43.8 \%)$ had an abnormal profile; 10 fetuses (15.6\%) presented with a flat forehead, and $17(26.6 \%)$ showed a vertical forehead. A flat occiput was described in $15.6 \%$ (n $=10$ ). Fetal cleft lip and palate was identified postnatally in 19 fetuses (29.7\%) (Table 3). In contrast with ultrasound findings, 48 fetuses $(75.0 \%)$ showed abnormal anatomical ocular and orbital findings. Forty-seven fetuses (73.4\%) were diagnosed with ear malformation, and 41 fetuses (64.1\%) with nasal malformation. Autopsy data revealed micrognathia in 32 fetuses $(50 \%)$; whereas, microstomia was diagnosed in 27 cases $(42.2 \%)$.

\section{Trisomy $21(n=302)$}

Brachycephaly was diagnosed prenatally in 42 fetuses $(13.9 \%)$. Besides a flat profile in $29.1 \%(\mathrm{n}=88)$, nuchal edema $(\mathrm{n}=69,22.8 \%)$ was a frequent marker for trisomy 21. Sonographically detected ocular-orbital abnormalities and nasal malformations were rare, with 13 occurrences $(4.3 \%)$ each, and ear malformations $(\mathrm{n}=1,0.3 \%)$ were very rare. Macroglossia $(n=7)$ and micrognathia $(n=7)$ were observed ultrasonographically in $2.3 \%$ of the fetuses and facial clefts in $1 \%(n=3)$.

Pathological and postnatal clinical examination $(\mathrm{n}=$ $106,35.1 \%$ ) revealed an abnormally shaped skull in 81 cases (76.4\%), with a majority of brachycephaly $(\mathrm{n}=71,67.0 \%)$. Fifty-five $(51.9 \%)$ had a flat profile, $17(16.0 \%)$ micrognathia, and $41(38.7 \%)$ macroglossia. Nuchal edema could be observed in 25 fetuses (23.6\%).

In contrast to sonographic indications, evaluation of the macroscopic anatomy showed a high percentage of ocularorbital $(\mathrm{n}=91,85.8 \%)$, nasal $(\mathrm{n}=84,79.2 \%)$, and ear malformations $(\mathrm{n}=41,38.7 \%)$. Among these malformations, hypertelorism $(\mathrm{n}=81,76.4 \%$ versus $\mathrm{n}=4,1.3 \%$ in 


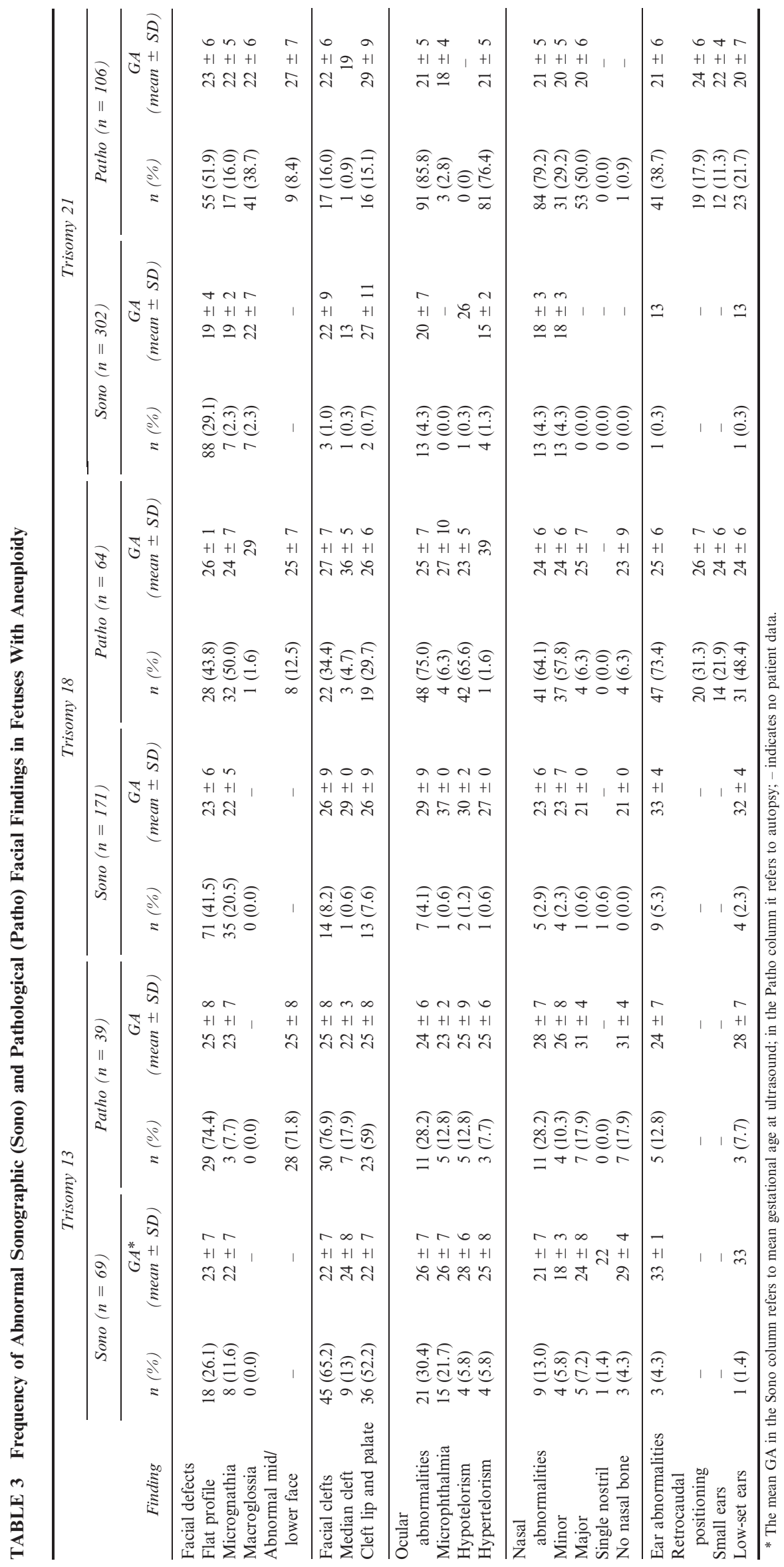


TABLE 4 Comparison of Ultrasound Diagnosis With Pathological Result Among the 209 Cases in Which Pathological Follow-Up Information Was Available*

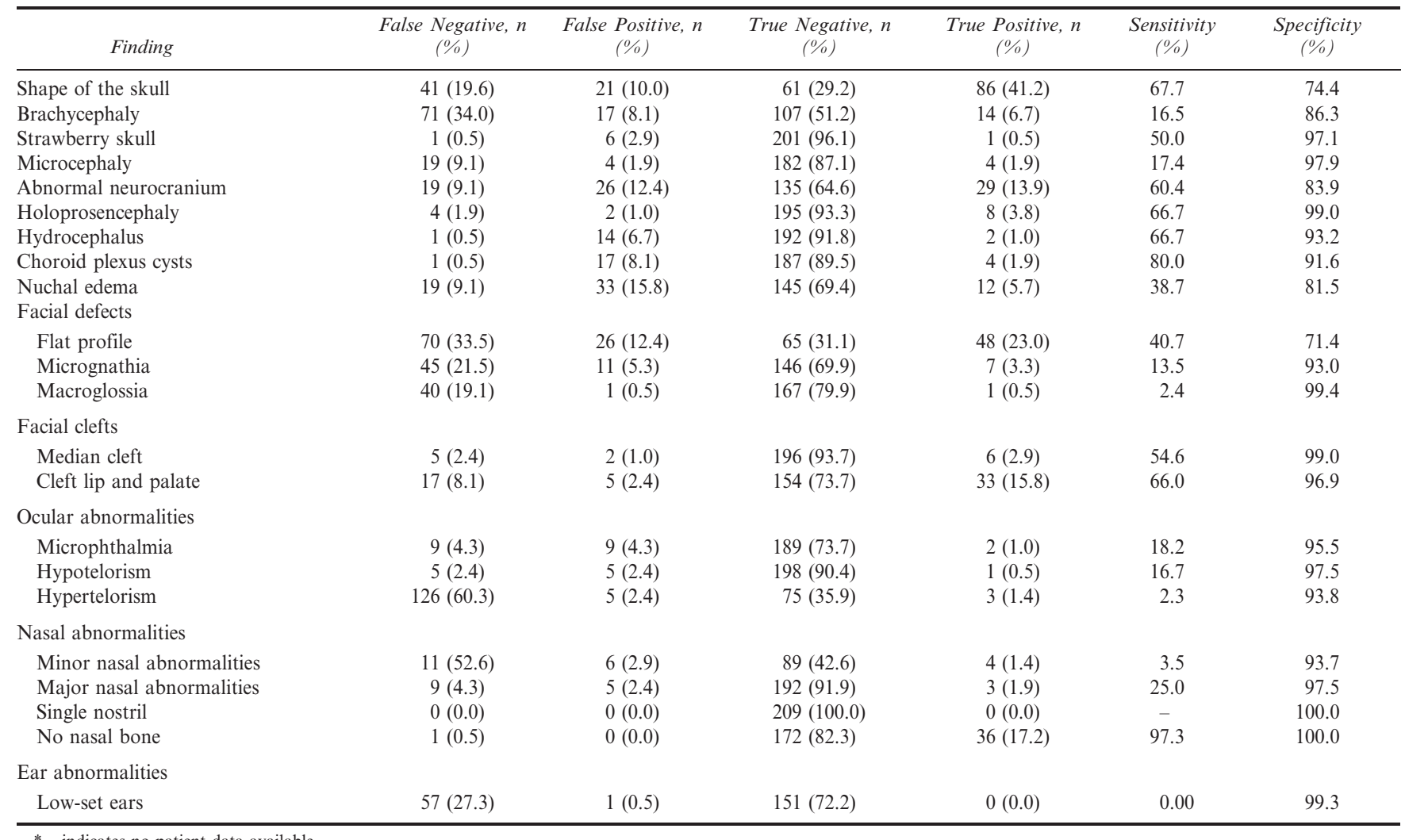

* - indicates no patient data available.

ultrasound) and mongoloid palpebral fissures $(\mathrm{n}=43$, $41.7 \%$ versus $\mathrm{n}=5,1.7 \%$ in ultrasound) were noted frequently; whereas, retrocaudally positioned ears $(n=19$, $17.9 \%$ versus $\mathrm{n}=0,0 \%$ in ultrasound), low-set ears $(\mathrm{n}=$ $23,21.7 \%$ versus $\mathrm{n}=1,0.3 \%$ in ultrasound), low nasal root $(\mathrm{n}=19,18.4 \%$ versus $\mathrm{n}=1,0.3 \%$ in ultrasound $)$, and flat nasal bridge $(\mathrm{n}=39,37.9 \%$ versus $\mathrm{n}=1,0.3 \%$ in ultrasound) were seen less frequently. An anteversion nostril $(\mathrm{n}=2,22.3 \%)$ and triangular nostril $(\mathrm{n}=16$,
$15.5 \%)$ were described only in the clinical pathological or postnatal examination.

In all 209 cases in which information from a pathological follow-up after ultrasound was available, the comparisons of the ultrasound diagnosis and pathological results were analyzed (Table 4). All sonographic findings were compared with the corresponding clinical conditions regarding accuracy (Fig. 1). One has to take into account that it was difficult for four reasons to make a clear statement about

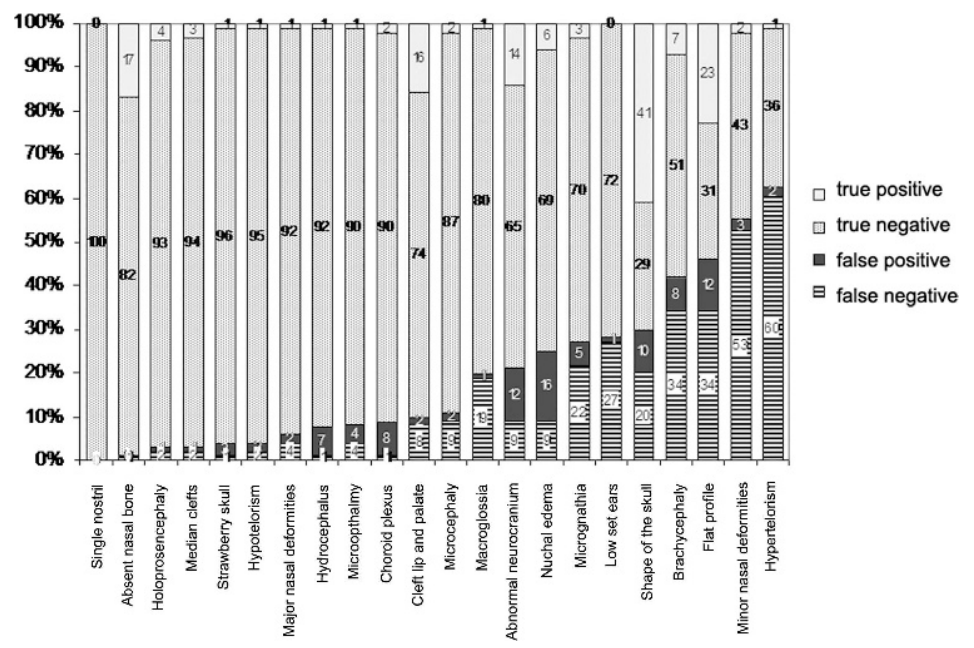

FIGURE 1 Comparison of ultrasound diagnosis with pathological follow-up among the 209 fetuses that underwent both, $n$ (\%). 
sensitivity and specificity. First, not all the women who were investigated during the study period (approximately 30,000 ) could be reviewed. Second, because this study involved a level III hospital, there was already a positive selection for fetuses at risk. Third, not all sonographic findings could be compared with postnatal autopsy results, and fourth, the medical technology experienced an impressive innovation in the three decades spanned by the study.

\section{Discussion}

Facial dysmorphisms seen in individuals with trisomies 13,18 , or 21 vary considerably. As a result of continuous advancements in ultrasound techniques, it has become possible to detect craniofacial malformations as early as the 11th week of gestation. In the literature, the largest karyotyped series of fetuses with sonographically detected craniomaxillofacial anomalies included 146 cases (Nicolaides et al., 1993a). The present study involved 559 trisomic fetuses.

\section{Ocular Abnormalities}

Ocular and orbital anomalies have been associated with several chromosomal abnormalities. According to the studies by Denis et al. (1993) and Trout et al. (1994), the inner and outer orbital measurements are useful for identifying fetuses with chromosomal defects. Similar to the findings of Nicolaides et al. (1993b), the occurrence of ocular and orbital pathology (especially microphthalmia and hypotelorism) was about $30 \%$ at sonography as well as at autopsy in trisomy 13 fetuses (Table 3). In a pathomorphological study, Siliaeva (1990) found ocular pathologies such as dysplasia of the retina, colobomas, cataract, and luxations of the lens in 25 out of 28 trisomy 13 fetuses $(89.3 \%)$. In contrast with the findings between sonography and autopsy in trisomy 13 fetuses, there was a large discrepancy between clinical pathology and ultrasound examination in trisomy 18 and 21 fetuses, with only $70 \%$ (trisomy 18) to $80 \%$ (trisomy 21) of the ocular pathology being demonstrated by ultrasonography in this study.

\section{Nasal Abnormalities}

Absence and hypoplasia of the nasal bones have been proposed recently as important markers for the detection of trisomy 21 (Bunduki et al., 2003; Vintzileos et al., 2003; Zoppi et al., 2003). In order to be accurate, this finding must be assessed using a midsagittal section of the face (Bergé et al., 2001). One limitation of our study is that the assessment of this sonographic marker may not be optimal because the data were collected over a long period of time, and a specific effort to examine nasal bones with current imaging standards was not part of our examination protocol.

\section{Ear Abnormalities}

Abnormally small ears have been described previously in fetuses with aneuploidy (Birnholz and Farrell, 1988; Lettieri et al., 1993; Awwad et al., 1994; Yeo et al., 2003). According to a study by Yeo et al. (2003), a short ear length - below the 10th percentile for gestational age - was accepted as a sensitive marker for trisomy $18(\mathrm{n}=26 / 27$, $96.3 \%$ ); whereas, in a study by Chitkara et al. (2002), a short ear was a negative marker for fetuses with trisomy 18 $(\mathrm{n}=0 / 4)$ and a positive marker for 3 out of 19 trisomy 21 fetuses $(15.8 \%)$. For trisomy 21, this was confirmed by Vintzileos and Egan (1995) in a prospective study.

In a previous study, low-set ears were found to be one of the most frequent external anomalies $(n=24,77.4 \%)$ in autopsy cases with trisomy 18 (Kinoshita et al., 1989). Similarly, almost $50 \%$ of our trisomy 18 cases were found at autopsy to have low-set ears.

In trisomy 21 fetuses at 11 to 14 weeks' gestation, ear length is reduced; however, the degree of deviation from normal has been found to be too small for this marker to be useful in screening for trisomy 21 (Sacchini et al., 2003).

\section{Facial Clefts}

In agreement with a previous study, the highest rate of median clefts revealed by ultrasound was found in fetuses with trisomy $13(\mathrm{n}=8 / 28,28.6 \%)$ (Bergé et al., 2001); whereas, the incidence of cleft lip and palate was quite uncommon in trisomy 21 (1\%) (Lopoo et al., 1999). The importance of characterizing the type of facial cleft was demonstrated by Nyberg et al. (1995), indicating that the type and extension of the cleft correlate with fetal outcome and karyotype abnormalities. In a study to determine the correlation between prenatal diagnosis and postnatal findings, Sohan et al. (2001) could demonstrate that ultrasound is a useful tool in screening for cleft lip with or without cleft palate but not for an isolated cleft palate. Nevertheless, even an isolated case of cleft lip was thought to be more at risk for a chromosomal abnormality (Nyberg et al., 1995; Bergé et al., 2001).

\section{Abnormal Profile/Micrognathia}

The facial profile of fetuses with a trisomic condition can be characterized by an insufficient configuration of the nose or by micrognathia with markedly receding chin and an unusually small mandible. Micrognathia occurs secondary to abnormalities of the first branchial arch caused by deficiency or insufficient migration of neural crest cells in the fourth week of gestation (Mernagh et al., 1999). Besides trisomies 13 and 18, micrognathia is often part of other syndromes or sequences, such as Treacher Collins syndrome, Goldenhar syndrome, and Seckel or Pierre Robin sequence (Nicolaides et al., 1993b; Bromley and Benacer- 
raf, 1994). Regarding abnormal profiles, the results of this study - in which sonographic findings like micrognathia, a flat profile, and macroglossia are associated with an abnormal karyotype in $26 \%$ to $42 \%$ of the fetusescorrespond with the literature, in which the equivalent figure is $25 \%$ to $40 \%$ of fetuses (Benacerraf et al., 1986; Nicolaides et al., 1993a; Turner and Twining, 1993; Bromley and Benacerraf, 1994).

Sonographic diagnosis of fetal micrognathia should, therefore, lead to a further search for evidence of other, possibly associated anomalies; if positive, determining karyotype is highly recommended.

In summary, some isolated prenatal sonographic findings, such as facial clefts and profile abnormalities, are not necessarily indicative of aneuploidy; whereas, multiple facial abnormalities increase the likelihood of a trisomic condition (Nicolaides et al., 1992; Nicolaides et al., 1993b; Nyberg et al., 1993; Lehman et al., 1995; Hill, 1996; Hafner et al., 1997; Shields et al., 1998; Bergé et al., 2001). A detailed facial scan therefore improves the detection of a trisomy.

In accordance with the literature (Nyberg and Souter, 2001), sonographically detected facial pathology can be obtained in $90 \%$ of fetuses with trisomy 13 , in $60 \%$ to $80 \%$ of fetuses with trisomy 18 , and in $50 \%$ to $70 \%$ of fetuses with trisomy 21 . An equally high identification rate is possible by evaluation of the facial pathology in fetuses with trisomy 13 and 18 . Therefore, cytogenetic evaluation should be recommended when facial abnormalities are diagnosed prenatally.

This study confirms that craniofacial abnormalities are present in a substantial proportion of fetuses with trisomies 21,18 , and 13. Thus, a detailed ultrasonographic evaluation of the fetal cranium and face should be performed in every fetal anatomical survey, and prenatal diagnosis of craniofacial abnormalities should prompt consideration of a karyotype.

Acknowledgment. We thank Prof. Knöpfle, M.D., from the Institute of Pathology, Medical Faculty of the University of Bonn (Director Prof. R. Buettner, M.D.), for her help in collecting the autopsy data.

\section{REFERENCES}

Awwad JT, Azar GB, Karam KS, Nicolaides KH. Ear length: a potential sonographic marker for Down syndrome. Int $J$ Gynaecol Obstet. 1994;44:233-238.

Benacerraf BR, Frigoletto FD Jr, Greene MF. Abnormal facial features and extremities in human trisomy syndromes: prenatal US appearance. Radiology. 1986;159:243-246.

Bergé SJ, Plath H, van de Vondel PT, Appel T, Niederhagen B, Von Lindern JJ, Reich RH, Hansmann M. Fetal cleft lip and palate: sonographic diagnosis, chromosomal abnormalities, associated anomalies, and postnatal outcome in 70 fetuses. Ultrasound Obstet Gynecol. 2001;18:422-431.

Birnholz JC, Farrell EE. Fetal ear length. Pediatrics. 1988;81:555-558.
Bromley B, Benacerraf BR. Fetal micrognathia: associated anomalies and outcome. J Ultrasound Med. 1994;13:529-533.

Bunduki V, Ruano R, Miguelez J, Yoshizaki CT, Kahhale S, Zugaib M. Fetal nasal bone length: reference range and clinical application in ultrasound screening for trisomy 21. Ultrasound Obstet Gynecol. 2003;21:156-160.

Chitkara U, Lee L, Oehlert JW, Bloch DA, Holbrook RH Jr, El-Sayed YY, Druzin ML. Fetal ear length measurement: a useful predictor of aneuploidy? Ultrasound Obstet Gynecol. 2002;19:131-135.

Denis D, Faure F, Volot F, Scheiner C, Boubli L, Dezard X, Saracco JB. Ocular growth in the fetus. 2. Comparative study of the growth of the globe and the orbit and the parameters of fetal growth. Ophthalmologica. 1993;207:125-132.

Hafner E, Sterniste W, Scholler J, Schuchter K, Philipp K. Prenatal diagnosis of facial malformations. Prenat Diagn. 1997;17:51-58.

Hansmann M, Hackelöer BJ, Staudach A. Ultraschalldiagnostik in Geburtshilfe und Gynäkologie. Lehrbuch und Atlas. Berlin: SpringerVerlag; 1991.

Hill LM. The sonographic detection of trisomies 13, 18, and 21. Clin Obstet Gynecol. 1996;39:831-850.

Kinoshita M, Nakamura Y, Nakano R, Morimatsu M, Fukuda S, Nishimi Y, Hashimoto T. Thirty-one autopsy cases of trisomy 18: clinical features and pathological findings. Pediatr Pathol. 1989;9: 445-457.

Lehman CD, Nyberg DA, Winter TC 3rd, Kapur RP, Resta RG, Luthy DA. Trisomy 13 syndrome: prenatal US findings in a review of 33 cases. Radiology. 1995;194:217-222.

Lettieri L, Rodis JF, Vintzileos AM, Feeney L, Ciarleglio L, Craffey A. Ear length in second-trimester aneuploid fetuses. Obstet Gynecol. 1993;81:57-60.

Lopoo JB, Hedrick MH, Chasen S, Montgomery L, Chervenak FA, Goldstein R, Hoffman WY, Harrison MR, Longaker MT. Natural history of fetuses with cleft lip. Plast Reconstr Surg. 1999;103: 34-38.

Mernagh JR, Mohide PT, Lappalainen RE, Fedoryshin JG. US assessment of the fetal head and neck: a state-of-the-art pictorial review. Radiographics. 1999;19(spec no):S229-S241..

Nicolaides KH, Salvesen DR, Snijders RJ, Gosden CM. Fetal facial defects: associated malformations and chromosomal abnormalities. Fetal Diagn Ther. 1993a;8:1-9.

Nicolaides KH, Shawwa L, Brizot M, Snijders R. Ultrasonographically detectable markers of fetal chromosomal defects. Ultrasound Obstet Gynecol. 1993b;3:56-69.

Nicolaides KH, Snijders RJ, Gosden CM, Berry C, Campbell S. Ultrasonographically detectable markers of fetal chromosomal abnormalities. Lancet. 1992;340:704-707.

Nyberg DA, Kramer D, Resta RG, Kapur R, Mahony BS, Luthy DA, Hickok D. Prenatal sonographic findings of trisomy 18: review of 47 cases. J Ultrasound Med. 1993;12:103-113.

Nyberg DA, Sickler GK, Hegge FN, Kramer DJ, Kropp RJ. Fetal cleft lip with and without cleft palate: US classification and correlation with outcome. Radiology. 1995;195:677-684.

Nyberg DA, Souter VL. Sonographic markers of fetal trisomies: second trimester. J Ultrasound Med. 2001;20:655-674.

Rasmussen SA, Wong LY, Yang Q, May KM, Friedman JM. Populationbased analyses of mortality in trisomy 13 and trisomy 18. Pediatrics. 2003;111:777-784.

Sacchini C, El-Sheikhah A, Cicero S, Rembouskos G, Nicolaides KH. Ear length in trisomy 21 fetuses at 11-14 weeks of gestation. Ultrasound Obstet Gynecol. 2003;22:460-463.

Shields LE, Carpenter LA, Smith KM, Nghiem HV. Ultrasonographic diagnosis of trisomy 18: is it practical in the early second trimester? J Ultrasound Med. 1998;17:327-331.

Siliaeva NF. Eye developmental defects in Patau's syndrome (trisomy 13). Oftalmol Zh. 1990;7:423-426.

Sohan K, Freer M, Mercer N, Soothill P, Kyle P. Prenatal detection of facial clefts. Fetal Diagn Ther. 2001;16:196-199. 
Sonek JD, Nicolaides KH. Prenatal ultrasonographic diagnosis of nasal bone abnormalities in three fetuses with Down syndrome. Am J Obstet Gynecol. 2002;186:139-141.

Trout T, Budorick NE, Pretorius DH, McGahan JP. Significance of orbital measurements in the fetus. J Ultrasound Med. 1994;13:937-943.

Turner GM, Twining P. The facial profile in the diagnosis of fetal abnormalities. Clin Radiol. 1993;47:389-395.

Vintzileos A, Walters C, Yeo L. Absent nasal bone in the prenatal detection of fetuses with trisomy 21 in a high-risk population. Obstet Gynecol. 2003;101:905-908.
Vintzileos AM, Egan JF. Adjusting the risk for trisomy 21 on the basis of second-trimester ultrasonography. Am J Obstet Gynecol. 1995;172: 837-844.

Yeo L, Guzman ER, Day-Salvatore D, Walters C, Chavez D, Vintzileos AM. Prenatal detection of fetal trisomy 18 through abnormal sonographic features. J Ultrasound Med. 2003;22:581-590, quiz 591-592.

Zoppi MA, Ibba RM, Axiana C, Floris M, Manca F, Monni G. Absence of fetal nasal bone and aneuploidies at first-trimester nuchal translucency screening in unselected pregnancies. Prenat Diagn. 2003;23: 496-500. 